đạt được giá trị hội tụ và giá trị phân biệt. Đặt ở bối cảnh hiện tại, việc tiêm chủng vắc-xin ngừa COVID-19 là giải pháp quan trọng nhất ngăn chặn dịch bệnh trong khi vẫn tồn tại một tỉ lệ do dự tiêm chủng trong dân số, nghiên cứu cung cấp công cụ cần thiết với độ tin cậy cao để đánh giá mức độ chấp nhận tiêm chủng vắc-xin COVID-19 và các yếu tố ảnh hưởng, giúp đưa ra các chiến lược hành động phù hợp, hiệu quả, nâng cao tỉ iệ tiêm chủng vắc-xin phòng ngừa COVID-19 đạt mục tiêu miển dịch cộng đồng.

Tuy nhiên, thang đo xây dựng được đánh giá đạt độ tin cậy và tính giá trị cho đối tượng sinh viên. Trong trường hợp áp dụng thang đo cho những đối tượng khác (người dân, cán bộ y tế...) cần có những điều chỉnh phù hợp và được thẩm định lại về độ tin cậy và tính giá trị. Với giới hạn về thời gian tiến hành nghiên cứu, giá trị dự báo của thang đo về mức độ chấp nhận tiêm chủng vắc-xin chưa được đánh giá. Do đó các nghiên cứu trong tương lai có thể khảo sát giá trị dự báo của thang đo để có bức tranh toàn cảnh hơn về giá trị của thang đo.

\section{KẾT LUẬN}

Thang đo đánh giá mức độ chấp nhận tiêm chủng vắc-xin COVID-19 trên đối tượng sinh viên đã được xây dựng với 5 nhân tố tiền đề tâm lý tiêm chủng bao gồm sự tin tưởng, sự cân nhắc, trách nhiệm cộng đồng, sự tự mãn và hạn chế và 15 biến quan sát. Các kết quả kiểm định cho thấy thang đo đạt độ tin cậy và độ giá trị cao. Thang đo có thể sử dụng trong tương lai để khảo sát mức độ chấp nhận tiêm chủng vắc-xin COVID-19 trên đối tượng sinh viên và các yếu tố liên quan cũng như làm cơ sở đề ra các giải pháp can thiệp phù hợp.

\section{TÀI LIÊUU THAM KHẢO}

1. Betsch C. et al. (2018), "Beyond confidence: Development of a measure assessing the $5 \mathrm{C}$ psychological antecedents of vaccination", PloS one. 13 (12), pp. e0208601.

2. Dror A. A. et al. (2020), "Vaccine hesitancy: the next challenge in the fight against COVID-19", Eur J Epidemiol. 35 (8), pp. 775-779.

3. Hair J., Anderson, R., Tatham, R. and Black, W. (1998), Multivariate data analysis, Prentice Hall, New Jersey.

4. Kanyike A. M. et al. (2021), "Acceptance of the coronavirus disease-2019 vaccine among medical students in Uganda", Tropical Medicine and Health. 49 (1), pp. 1-11.

5. Lurie N. et al. (2020), "Developing Covid-19 vaccines at pandemic speed", New England Journal of Medicine. 382 (21), pp. 1969-1973.

6. MacDonald N. E. (2015), "Vaccine hesitancy: Definition, scope and determinants", Vaccine. 33 (34), pp. 4161-4164.

7. Mascarenhas A. K. et al. (2021), "Dental students' attitudes and hesitancy toward COVID-19 vaccine", Journal of Dental Education.

8. WHO covid-19 vaccines, https://www.who.int/ emergencies/diseases/novel-coronavirus-

2019/covid-19-vaccines, ngày truy cập 9/5/2021.

\title{
ĐộT BIẾN GEN UROPORPHYRINOGEN III COSYNTHASE TRÊN MộT BÉ GẢ́I MẮC BỆNH PORPHYRIA TẠO HỒNG CẦU BẨM SINH TẠI VIỆT NAM
}

\section{TÓM TẮT}

Mở đâu: Bệnh Porphyria tạo hộng cầu bẩm sinh (CEP) là bệnh dỉ truyền lặn trên nhiễm sắc thể thường do rối loạn của quá trình chuyển hóa porphyrin gậy thiếu hụt uroporphyrinogenIII cosynthase (UROS) dẫn đến sự tích lũy uroporphyrinogen I trong tủy xương, gan và các mô. Ca lâm sàng: Mô tả đặc điểm lâm sàng và đột biến gen trên một bệnh nhân người Việt đến khám tại Bệnh viện Da Liễu Trung Uơng. Bé gái 5 tuổi có tình trạng da bị nhạy cảm nặng với ánh sáng, cụ thể là các thương tổn bóng nưởc và rậm lông ở

\footnotetext{
*Trường Đại học Y khoa Phạm Ngọc Thạch, TP. Hồ Chí Minh

Chịu trách nhiệm chính: Phạm Hiếu Liêm

Email: drkimdao@pnt.edu.vn

Ngày nhận bài: 3.6.2021

Ngày phản biên khoa họ: 31.7.2021

Ngày duyệt bài: 6.8.2021
}

\section{Đào Hoàng Thiên Kim*, Phạm Hiếu Liêm*}

những vùng phơi bày ánh sáng. Lân đầu tiên chúng tôi mô tả đột biến gen UROS trên môt bênh nhân Đông Nam Á và thực hiện thêm chẩn đoán phân tử để xác định cả những người lành ở thể dị hợp không triệu chứng đang mang mầm đột biến trong gia đình của người bệnh CEP. Để làm rõ cơ sở phân tử đâu tiên của gia đình người Việt này, chúng tôi đã tiến hành nhận dạng UROS đột biến và đo lường hoạt động của uroporphyrinogen III cosynthase trên bệnh nhi CEP. Đột biến sai nghĩa đã được phát hiện là một đột biến thay thế $\mathrm{G}$ thành $\mathrm{T}$ tại nucleotide 11.776 và kết quả là valin bi thay thế thành phenylalanin tại codon 3 của exon 2. Chúng tôi ghi nhận bệnh nhân bị đột biến lặn thể đồng hợp còn bố mẹ của bé ở dạng dị hợp. Hoạt động của đột biến enzym UROS được biểu hiện trong Escherichia coli bị giảm còn $16,1 \%$, chứng tỏ sự giảm rõ rêt hoat đônng của UROS là kết quả chính yếu từ đôt biến gen gây ra bệnh CEP. Kết luận: Phân tích đột biến gen gây bênh CEP được xem là quan trong trong việc quản lý bệnh. Tham vấn di truyền cho toàn bộ 
các thành viên của gia đình có người bệnh và cả trong chẩn đoán tiền sản là thật sự cần thiết khi gặp phải bệnh hiếm này.

Tư khóa: Bệnh tạo hồng câu bẩm sinh; Uroporphyrinogen III cosynthase; Deficiency; Nhạy cảm ánh sáng; Đột biến.

\section{SUMMARY \\ A VIETNAMESE GIRL WITH MUTATION OF THE UROPORPHYRINOGEN III COSYNTHASE GENE: CONGENITAL ERYTHROPOIETIC PORPHYRIA}

Background: Congenital erythropoietic porphyria (CEP) arises from an autosomal recessive inherited disorder of the porphyrin metabolism, which leads to the accumulation of uroporphyrinogen I in bone marrow, skin and several other tissues by a deficiency of uroporphyrinogen III cosynthase (UROS). Case report: To describe clinical feature and gene mutation in a patient treated at National Hospital of Dermatology and Venereology. A five-year-old Vietnamese girl suffering from severe cutaneous photosensitivity with skin fragility, bullous lesions and hypertrichosis on light-exposed areas. We described for the first time a mutation in the UROS gene in a Southeast Asian patient and a molecular diagnosis for the identification of clinically asymptomatic heterozygous mutation carriers and families with CEP. To clarify the first molecular basis of Vietnamese family, identification of UROS mutation, and measurement activity of uroporphyrinogen III cosynthase in a patient with CEP were performed. A missense mutation in the UROS gene was identified as a transversion of $\mathrm{G}$ to $\mathrm{T}$ at nucleotide 11,776 , resulting in a substitution of valine by phenylalanine at codon 3 of exon 2. The patient showed a homozygous mutant profile, and the heterozygous state was observed in the parents. The activity of mutated UROS expressed in Escherichia coli was less than $16.1 \%$ that of the control, indicating that the markedly reduced activity of UROS from genetic mutation is responsible for CEP. Conclusions: The mutational analysis of gene causing CEP is important in the patient's disease management. Genetic counseling of the family and prenatal diagnosis is strongly recommended in this rare disease.

Keywords: Congenital erythropoietic porphyria; Uroporphyrinogen III cosynthase; Deficiency; Photosensitivity; Mutation.

\section{I. ĐĂT VẤN ĐỀ}

Bệnh Porphyria tạo hồng cầu bẩm sinh (CEP) hay bênh Gunther là bênh di truyền lặn trên nhiễm sắc thể thường do đột biến gen làm suy giảm trầm trọng hoạt động của enzyme uroporphyrinogen III cosynthase (UROS). CEP là một rối loạn rất hiếm gặp với tỷ lệ ước tính khoảng 1/1.000.000 [1]. Cho đến nay vẫn chưa có số liệu chính xác về tỷ lệ mắc của $C E P$, tuy nhiên có khoảng 200 trường hợp đã được báo cáo trên toàn thế giới $[2,4]$. Trên lâm sàng, CEP biểu hiện bằng tình trạng nhạy cảm ánh sáng dữ dội trên một làn da vố cùng mỏng manh, cụ thể là sự tồn tại các thương tổn bóng nước, rậm lông, sẹo ở những vùng phơi bày ánh sáng kèm theo tình trạng rụng tóc và răng màu đỏ nâu. Trên phương diện hóa sinh, đặc trưng của bệnh này là sự tích lũ̃y quá mức uroporphyrinogen I và coproporphyrin trong huyết tương, các mô và hồng cầu, từ đó dẫn đến việc gia tăng bài tiết các chất này vào trong phân và nước tiểu. Người bệnh có thể ở dạng đồng hợp với cùng một loại đồt biến hay dang di hợp với 2 loai đột biến khác nhau và mức độ trâm trọng của bệnh tỷ lệ nghịch với độ hoạt động của lượng enzyme UROS còn lại $[2,10]$. Ngoài ra, độ nặng còn được phân loại theo tuổi khởi phát, mức độ thiếu máu tán huyết, có tổn thương da, lách to và tình trạng hủy xương [2]. Các bệnh nhân CEP thường bị giảm tuổi thọ tùy thuộc vào mức độ của tán huyết và xử trí các nhiễm trùng thứ phát.

\section{BÁO CÁO MộT TRƯờNG HợP}

Chúng tôi đã tiếp nhận một bé gái 5 tuổi có tiền sử nước tiểu màu hồng ngay từ lúc mới sinh. Bệnh khởi phát nặng khi bé được 10 tháng tuổi. Khi đó bé đã mọc răng sũ̃a màu đỏ nâu. Ngoài ra, bé còn chịu đựng một tình trạng bỏng rát, hồng ban và phù nề trên mặt, cố, cánh tay và cẳng chân trong vòng vài phút sau khi tiếp xúc trực tiếp với ánh sáng mặt trời ở thời kỳ nhũ nhi. Các mụn nước hoặc bóng nước dưới thượng bì tiến triển thành loét, đóng vảy rồi lành sẹo kèm theo tăng sắc tố hay giảm sắc tố (Hình 1a). Thương tổn xuất hiện liên tục và trở nên trầm trọng vào những tháng mùa xuân và mùa hè. Rậm lông phát triển trên những vùng da không được che phủ. Ngoài ra, hiện tượng lách to cũng được quan sát thấy trền bệnh nhân này. Porphyrin niệu tăng cực cao đến $16 \mu \mathrm{mol} / \mathrm{dl}$ trong đó chủ yếu là coproporphyrins và uroporphyrins. Tuy nhiên, nồng độ cụ thể của từng loại porphyrin lại không được phân tích rõ khi thực hiện xét nghiệm. Các triệu chứng da nhạy cảm ánh sáng nặng, bỏng rộp ở vùng da phơi bày ánh sáng trực tiếp, tiên sử tã lót có nước tiểu màu hồng kèm theo tình trạng tích luỹ các porphyrin trong máu và các mô, đặc biệt là dấu chứng răng sữa màu đỏ nâu (Hình $1 \mathrm{~b}$ ) đã giúp chúng tôi trong việc chẩn đoán bệnh CEP.

Các dữ liệu lâm sàng và sinh hóa của bệnh nhân được tóm tắt trong bảng 1 . Trên bệnh nhi này, chỉ với sự tránh tia cực tím và ánh sáng khả kiến một cách nghiêm ngặt kèm thoa kem chống nắng, uống $\beta$-carotene và kháng sinh để ngăn 
ngừa nhiễm trùng da, các bóng nước đã được chữa lành và để lại các sẹo tăng sắc tố trên vùng da bị tổn thương mà không cần phải tiến hành biện pháp truyền máu nào cho bé.

Sau khi thực hiện phân tích gen UROS của bênh nhân CEP. DNA của các exon 2-10 bao gồm tiếp hợp ghép nối của tất cả các exon được khuếch đại bằng PCR và sau đó được giải trình tự. Một đột biến sai nghĩa đã được phát hiện trên bệnh nhân này là đột biến thay thế $\mathrm{G}$ thành $\mathrm{T}$ tại nucleotide 11.776 và dẫn đến kết quả là một acid amin valin bị thay thế thành phenylalanin tại codon 3 của exon 2 (Hình 2). Kết quả đã phản ánh một tình trạng đột biến lặn ở thể đồng hợp trên bệnh nhân này. Sau đó, chúng tôi cũng tiến hành phân tích gen UROS của thân nhân người bệnh và ghi nhận được cha mẹ bệnh nhi đều là dạng dị hợp tử. Anh trai của bệnh nhi đã qua đời vì một cằn bệnh tương tự với các triệu chứng và những bất thường như bệnh nhi. Điều đó cho thấy rằng có lẽ người anh này cũng có đột biến gen y như vậy (V3F). Ngược lại, trên cơ sở phân tích phả hệ cả ba thế hệ, không tìm thấy người nào mắc bệnh tương tự. Để làm sáng tỏ mối quan hệ giữa kiểu gen và kiểu hình, chúng tôi đã xây dựng một pET-duet vector [8] mang đột biến CDNA của UROS và chuyển nó vào chủng Escherichia coli BL21. Các biểu hiện của UROS trong vi khuẩn được tạo ra ở $25^{\circ} \mathrm{C}$. Sau khi tinh sạch biểu hiện enzyme với các ion nickel (Qiagen Inc., Valencia, Calif., Mỹ), hoạt động của đột biến UROS (V3F) được so sánh với hoạt động enzyme bình thường theo phương pháp của Wright và Lim [11]. Hoạt động đặc trưng của UROS đột biến giảm còn $16,1 \%$ so với chứng.

\section{BÀN LUÂ̂N}

Trong nghiên cứu này, các phân tích đột biến gen UROS phát hiện đột biến (V3F) trong bộ gen DNA của một bệnh nhân CEP người Việt. Bệnh nhi ở thể đồng hợp tử với kiểu đột biến sai nghĩa V3F còn cha mẹ bé là người lành ở thể dị hợp tử chứa đột biến. Ngoại trừ cha mẹ của bé, không có bất kỳ thành viển nào trong gia đình được thực hiện chẩn đoán phân tử, nhưng anh trai của bệnh nhi đã qua đời với các triệu chứng tương tự như của bệnh nhi. Gia đình đã do dự trong việc trải qua các nghiên cứu sinh hóa thêm nhằm đánh giá hoạt động của enzyme còn lại trong việc mở rộng đánh giá tương quan kiểu gen và kiểu hình. Sự suy giảm, nhưng không phải là không có của UROS đưa đến kết quả chính là sự tích lũy porphyrin trong các mô. Sự vắng mặt hoàn toàn UROS có khả năng dẫn đến tử vong. Chúng tôi đã xây dựng đột biến CDNA và thể hiện protein tái tổ hợp trong $\mathrm{E}$. coli. Các UROS đột biến (V3F) cho thấy hoạt động của enzyme giảm thấp còn $16,1 \%$. Mặc dù tuổi khởi phát bệnh và các biểu hiện lâm sàng của CEP rất biến thiên từ chỉ tổn thương da đến thiếu máu tán huyết với mức độ từ nhẹ đến nặng ở những người lớn mắc bệnh CEP, biểu hiện nhạy cảm ánh sáng đã được ghi nhận rất sớm ngay sau khibệnh nhi này ra đời.

Hơn nữa, các biểu hiện lâm sàng nặng ở giai đoạn thơ ấu đã được quan sát thấy trên bệnh nhẩn này do suy giảm hoạt động enzyme của UROS. Sự thay thế của valin thành phenylalanin ở vị trí 3 đưa đến sự thay đổi của chuỗi bên các acid amin ky nước mà có thể đưa đến sự thay đổi cấu trúc tại N-terminus của UROS [5]. Đột biến này đã từng được mô tả trên một bệnh nhân người Nhật trước đây [9] và đột biến L4F đã được tìm thấy trên những bệnh nhân người Mỹ [2], cho thấy vùng $\mathrm{N}$-terminal của enzyme là khá quan trọng cho các phản ứng xúc tác. Chuỗi acid amin MKVLLL trên N-Terminus của UROS cũng được bảo tồn trên các động vật có vú và các loài sinh vật khác và cũng góp phần khẳng định đó là một vùng không thể thiếu. Dựa trên cấu trúc 3D của UROS [5], các acid amin được bảo tồn ở $\mathrm{N}$-terminus cuối tạo thành một $\beta$-sheet liên quan đến các vùng $a$-helix và $\beta$-sheet khác của enzyme và có thể đóng một vai trò quan trọng trong việc duy trì cấu trúc cơ bản của UROS. Các nghiên cứu hiện nay cho thấy sự thay đổi của nhóm isopropyl từ valin thành nhóm phenyl của phenylalanin làm giảm đáng kể hoat tính của enzyme, và các nhà nghiên cứu khác cũng báo cáo rằng sự thay đổi của nhóm isopropyl từ leucin thành nhóm phenyl ở acid amin kế tiếp (L4F) cũng làm giảm hoạt động enzyme [2]. Do đó, những thay đổi về cấu trúc nhỏ như những thay đổi của một nhóm ky nướcky nước tại N-terminus của protein có thể làm giảm đáng kể hoạt động của enzyme

Phương thức điêu trị bệnh di truyền CEP là tránh nắng, đặc biệt là dải sóng Soret từ 400$410 \mathrm{~nm}$ và truyền máu để làm giảm sự sản xuất porphyrin. Bên cạnh đó, việc sử dụng kem chống nắng, uống $\beta$-carotene, than hoạt hay chất gắn kết porphyrin cũng mang lại một hiệu quả tương đối hạn chế trong điều trị [2]. Trái lại, ghép tủy được xem là một phương thức điêuu trị thành công cho bệnh CEP [3]. Katugampola và các cộng sự đã báo cáo kết quả giảm mức porphyrin và sự nhạy cảm ánh sáng trên nhiều bệnh nhân 
được điều trị bằng phương pháp ghép tủy [3]. Hơn nữa, cách điều trị này còn làm giảm đáng kể tình trạng lách to và lượng porphyrin bài tiết cũng như làm giảm các thương tổn da do tiếp xúc với ánh nắng mặt trời trên các bệnh nhân CEP [3]. Vì vậy, ghép tủy là một trong các phương thức điều trị hữu hiệu cho bệnh nhân CEP mặc dù nó cần người hiến có HLA tương hợp. Trong tương lai, việc sử dụng công nghệ tế bào gốc với sự biểu hiện vector trung gian của bản sao UROS (UROS cDNA) có thể là một hướng điều trị mới [6].

Cho đến thời điểm hiện nay đã có khoảng 40 loại đột biến UROS được công bố. Trong số đó, C73R là đột biến thường gặp nhất và đưa đến nhiều kiểu hình trầm trọng trên các bệnh nhân CEP. Đột biến này đã được ghi nhận trên $1 / 3$ bệnh nhân CEP và $1 / 2$ các bệnh về alen tại các nước châu Âu [2]. Tuy nhiên, nó lại ít được báo cáo ở các nước thuộc khu vực chẩu Á. L237 và S47P vừa được phát hiện tại Tây Á [7]. Có 6 đột biến UROS được tìm thây trên các bệnh nhân người Nhật, trong số đó V3F là đột biến thể đồng hợp. Trong tất cả các nghiên cứu khác, bệnh nhân được phát hiện dưới dạng đột biến thể đồng hợp hay dị hợp ở giữa cẩu trúc chính của UROS [5].

Đây là bệnh nhân đầu tiên được chẩn đoán CEP tại khu vực Đông Nam Á và hiện không có những khiếm khuyết phân tử nào của gen UROS đang tồn tại liên quan đếnkiểu gen của UROS trong khu vực các quốc gia thuộc khu vực này.Đột biến V3F chưa từng được nhận diện ở chủng tộc Caucasian nhưng lại được tìm thấy trên một bệnh nhân người Nhật. Lý do cho sự hiện diện của đột biến V3F trên bệnh nhân Việt Nam và bệnh nhân Nhật Bản vẫn chưa được rõ ràng vì hai quốc gia vốn cách xa nhau về mặt địa lý nhưng có lẽ cả hai đã từng có chung một tổ tiên trong thời kỳ chiến tranh thế giới thứ hai.

\section{KẾT LUẬN}

Phân tích đột biến gen gây bệnh CEP được xem là quan trọng trong việc quản lý bệnh. Tham vấn di truyền cho toàn bộ các thành viên của gia đình có người bệnh và cả trong chẩn đoán tiền sản là thật sự cần thiết khi gặp phải bệnh hiếm này.

Bảng 1: Các đặc điểm lâm sàng và cận lâm sàng của bệnh nhần CEP

\begin{tabular}{|c|c|}
\hline $\begin{array}{c}\text { Đặc điểm lâm } \\
\text { sàng }\end{array}$ & $\begin{array}{c}\text { Đặc điểm cận lâm } \\
\text { sàng }\end{array}$ \\
\hline Thiếu máu + & RBC: $4.780 .000 / \mathrm{mm}^{3}$ \\
\hline Lách to + & HCT: $34,6 \%$ \\
\hline
\end{tabular}

\begin{tabular}{|c|c|}
\hline Răng màu đỏ nâu + & Hemoglobin: $10,3 \mathrm{~g} / \mathrm{dl}$ \\
\hline Rậm lông: mặt & $\mathrm{MCH}: 22,2 \mathrm{pg}$ \\
\hline $\begin{array}{c}\text { Nhạy cảm ánh sáng: } \\
\text { thương tổn da nặng, } \\
\text { bóng nước, sẹo }\end{array}$ & $\begin{array}{c}\text { Porphyrin toàn phần } \\
\text { niệu } 16 \mu \mathrm{mol} / \mathrm{dl} \text { Chứng } \\
(<10 \mathrm{nmmol} / \mathrm{dl})\end{array}$ \\
\hline Tăng sắc tố + & \\
\hline Tiêu huyết \pm & \\
\hline $\begin{array}{c}\text { Chức năng gan: } \\
\text { bình thương }\end{array}$ & \\
\hline
\end{tabular}

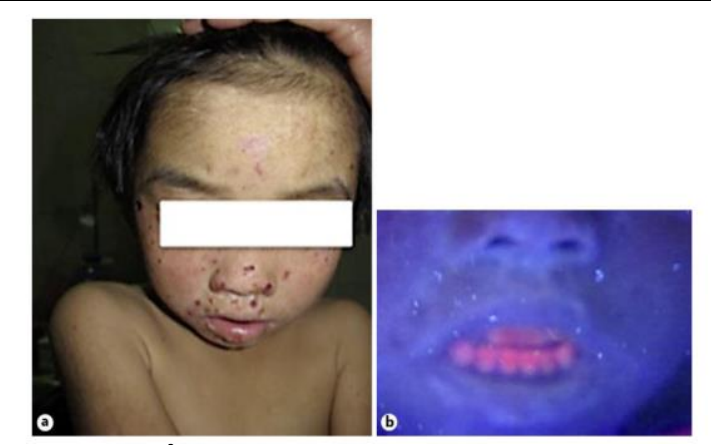

Hình 1: Ảnh chụp bệnh nhân CEP. a. Vêt loét đóng vảy và rậm lông ở tránb. Răng ánh màu đỏ nâu dưới đèn WOOD.
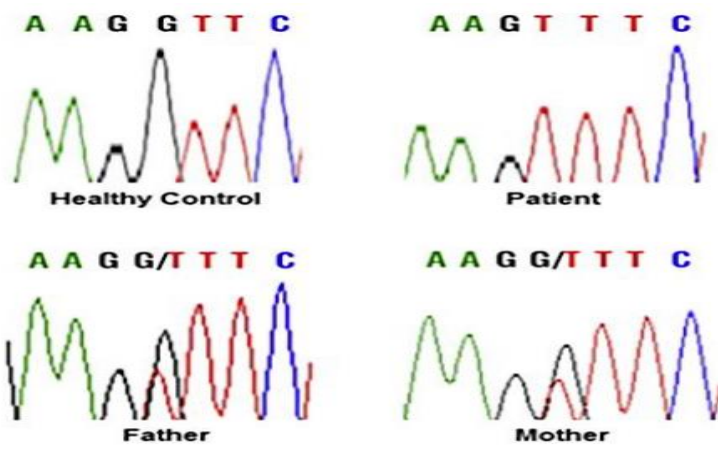

A A G G/T T T $\mathbf{C}$

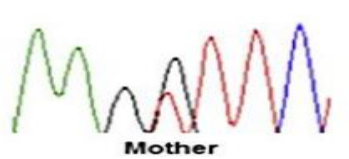

Hình 2: Trình tự nucleotide của exon 2 trên gen UROS của bệnh nhi, cha me bé và một người khỏe mạnh. Đột biến sai nghĩa V3F đột biến là đột biến thể đồng hợp dạng chuyển $G$ thành $T$

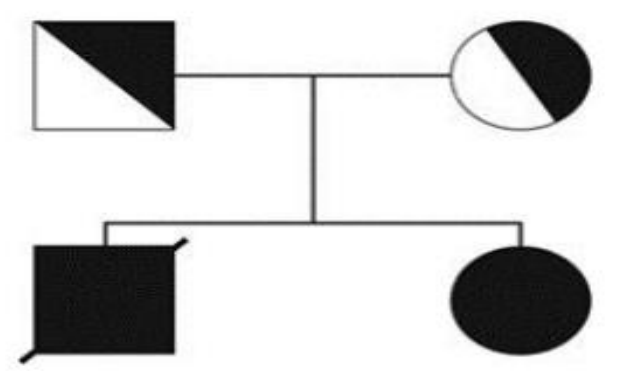

Hình 3: Sơ đồ phả hệ của bệnh nhân CEP. Bệnh nhi ở thể đồng hợp tử V3F. Anh trai của bệnh nhi đã qua đời vì một căn bệnh tương tự như người bệnh và cha mẹ của bệnh nhi đều ở dạng dị hợp không có triệu chứng. 


\section{TÀI LIÊU THAM KHẢO}

1. De, A.K., et al (2013). A Case of Congenital Erythropoietic Porphyria without Hemolysis. Indian J Dermatol, 58(5): p. 407.

2. Desnick RJ, Astrin KH (2002). Congenital erythropoietic porphyria: advances in pathogenesis and treatment. $\mathrm{Br}$ ] Haematol, 117:779-795.

3. Katugampola RP, Anstey AV, Finlay AY, Whatley S, Woolf J, Mason N, Deybach JC, Puy H, Ged C, de Verneuil H, Hanneken S, Minder $E$, Schneider-Yin $X$, Badminton MN (2012). A management algorithm for congenital erythropoietic porphyria derived from a study of 29 cases. Br J Dermatol, 167:888-900.

4. Maniangatt, S.C. et al (2004). A rare case of porphyria. Ann Acad Med Singapore,33(3): p. 359-61.

5. Mathews MA, Schubert HL, Whitby FG, Alexander KJ, Schadick K, Bergonia HA, Phillips JD, Hill CP (2001). Crystal structure of human uroporphyrinogen III synthase. EMBO J, 20:5832-5839.

6. Mazurier F, Géronimi F, Lamrissi-Garcia I, Morel C, Richard E, Ged C, Fontanellas A, MoreauGaudry F, Morey M, de Verneuil H (2001). Correction of deficient CD34+ cells from peripheral blood after mobilization in a patient with congenital erythropoietic porphyria. Mol Ther, 3:411-417.

7. Moghbeli M, Maleknejad M, Arabi A, Abbaszadegan MR (2012). Mutational analysis of uroporphyrinogen III cosynthase gene in Iranian families with congenital erythropoietic porphyria. Mol Biol Rep, 39:6731-6735.

8. Ohgari $Y$, Sawamoto M, Yamamoto M, Kohno H, Taketani S (2005). Ferrochelatase consisting of wild-type and mutated subunits from patients with a dominant-inherited disease, erythropoietic protoporphyria, is an active but unstable dimer. Hum Mol Genet, 14:327-334.

9. Takamura $\mathbf{N}$, Hombrados $I$, Tanigawa $K$, Namba $H$, Nagayama $Y$, de Verneuil $H$, Yamashita S (1997). Novel point mutation in the uroporphyrinogen III synthase gene causes congenital erythropoietic porphyria of a Japanese family. Am J Med Genet, 70:299-302.

10. Wiederholt $T$, Poblete-Gutiérrez $P$, Gardlo K, Goerz G, Bolsen K, Merk HF, Frank J (2006). Identification of mutations in the uroporphyrinogen III cosynthase gene in German patients with congenital erythropoietic porphyria. Physiol Res, 55(suppl 2): S85-S92.

\section{BƯớC ĐẦU ĐÁNH GIÁ HIỆU QUẢ ĐIỀU TRI CỦA DECITABINE TRÊN NGƯỜI BÊNH LOAN SINH TỦY TẠI BỆNH VIỆN TRUYỀN MÁU HUYẾT HỌC}

\section{TÓM TẮT}

Muc tiêu: Đánh giá hiệu quả điêu tri và độc tính của việc điêuu trị Decitabine trên người bệnh loạn sinh tủy (MDS). Đối tượng và phương pháp nghiên cứu: Mô tả hàng loạt ca, các người bệnh được chẩn đoán MDS, thỏa tiêu chuẩn nhân vào và được điều tri với Decitabine $20 \mathrm{mg} / \mathrm{m}^{2} /$ ngày x 5 ngày, từ tháng 01/2019 đến tháng 7/2021 tại bệnh viện Truyền máu Huyết học (BV.TMHH). Đánh giá đáp ứng điều trị theo IWG 2006. Kết quả: 32 người bệnh (18 nam, 14 nữ) được phân loại theo WHO 2016, chiếm tỉ lệ cao nhất là nhóm MDS tăng tế bào non-2 (MDS-EB2) $(56,2 \%)$ và nhóm nguy cơ rất cao theo IPSS-R (56,2\%). Người bênh được điêuu trị từ 1 đến 11 chu kỳ Decitabine với tỉ lệ đáp ứng toàn bộ (ORR: CR+PR) là 21,9\%; trong đó đạt đáp ứng hoàn toàn $(\mathrm{CR})$ là $12,5 \%$ và đạt đáp ứng một phân (PR) là 9,4\%. Đáp ứng tủy xương hoàn toàn (mCR) là $25 \%$. Nhóm ngưới bệnh điêu trị >4 chu kỳ

*Đại hoc Y Dước Tp. Hồ Chí Minh

**Bêenh viên Truyền máu - Huyết hoc.

Chịu trách nhiệm chính: Lê Thị Hà

Email: halethi1010@gmail.com

Ngày nhận bài: 4.6.2021

Ngày phản biên khoa hoc: 2.8.2021

Ngày duyệt bài: 10.8 .2021
Lê Thị Hà*, Trịnh Lê Quốc Vũ**, Huỳnh Thiện Ngôn**, Nguyễn Phương Liên**

có tỉ lê đạt $O R R, C R$; thời gian sống còn toàn bộ(OS); sống khồng tiến triển bệnh (PFS); sống không tiển triển thành $A M L(A M L F S)$ cao hơn nhóm điêu trị $\leq 4$ chu kỳ ( $p$ lần lượt: 0,$032 ; 0,009 ; 0,007 ; 0,01 ; 0,009$ ). Tỉ lệ người bệnh độc lập truyền hồng cẩu, tiếu cầu tăng theo chu kỳ, tại chu kỳ 6 cùng bằng $40 \%$. Thời gian theo dõi trung vi là 7 tháng với trung vị của OS; PFS; AMLFS lần lượt là: 12,3; 7,9; 11,6 (với độ tin cậy $95 \%)$. Nhóm người bệnh đạt $\mathrm{PR} / \mathrm{CR}$ có $\mathrm{OS}$ và̀ AMLFS kéo dài hơn nhóm không đạt ( $p$ lần lượt: 0,004 ; 0,016). Biến chứng độ III-IV thường gặp trong quá trình điều trị là: nhiếm trùng $68,7 \%$; giảm bạch cầu hat $68,7 \%$; giảm tiểu cầu $65,6 \%$; thiêu máu $56,2 \%$;. Tử vong do biến chứng điều trị là $18,7 \%$ (chủ yếu do biễn chứng nhiễm trùng kết hợp giảm bạch câuu hạt năng). Kết luân: Sử dụng Decitabine trong điều tri MỉS cho thây hiệu quả trong giảm nhu cầu truyền chể phẩm máu, giúp cải thiện huyết học, đồng thời giúp kéo dài thời gian OS, PFŚ, AMLFS cho người bệnh, đặc biêt ở nhóm người bênh có đáp ứng điêu trị.

Tư khóa: Loạn sinh tủy, decitabine

\section{SUMMARY \\ PRELIMINARY ASSESSMENT OF DECITABINE EFFECTIVENESS IN TREATMENT OF MYELODYSPLASTIC SYNDROMES AT BLOOD TRANSFUSION HEMATOLOGY HOSPITAL}

